\title{
FACEBOOK: AN EFFECTIVE WEB 2.0 TECHNOLOGY FOR BLENDED EFL CLASSROOMS IN INDONESIA
}

\author{
Husnawadi ${ }^{a}$ \\ UIN Mataram, husnawadi1985@uinmataram.ac.id \\ Nanang Sugianto \\ IKIP Mataram, nananggomong@gmail.com
}

\begin{abstract}
The $21^{\text {st }}$ century learning has been a landmark in the use of digital technologies that serve pedagogical purposes, which includes the proliferating use of blended learning (Henceforth BL). A mixture of face-to-face (FTF) and online learning (Internet Synchronous and Asynchronous media), BL strategy has gained its popularity in the sphere of English language teaching (Hereafter ELT) due to its effectiveness in promoting learners' language proficiency. However, the discussion on the extent to which e-learning mode plays role in English as a foreign language (Henceforth EFL) classrooms, particularly Indonesia, remains scantily documented; and a query on what can be an effective and efficient medium of e-learning in the strategy remains persistent in the foreign language context. With its popularity and preferred medium of communication among teenagers across the globe, especially Indonesia, Facebook (hereafter FB) can be an answer to such a question. Hence, drawing on the Indonesian ELT context, this paper discusses the nature of $\mathrm{BL}$; argues why $\mathrm{FB}$ can be an effective and efficient add-on to e-learning mode in the Blended ELT context; and presents an example of its application as applied in one of the authors' English-speaking classroom at a State University for Islamic Studies (UIN Mataram) and a reflection as the lecturer. This paper is expected to inform the English teaching practitioners or teachers on how to use social media, particularly $\mathrm{FB}$, to enhance the students' learning and learning outcomes particularly in Indonesian adult English classrooms.
\end{abstract}

Keywords: Blended learning, Facebook, EFL, and WEB 2.0.

\footnotetext{
Note: This article is an edited version of the artilce entitled "Facebook: An Effective E-learning Medium in the Blended English as Foreign Language Classrooms in Indonesian Higher Education Context" presented in an International conference at a local campus in Lombok. Due to its unpublished status and under the permission of the conference committee and for the sake of knowledge dissemination, this article, with some minor revisions and additions, is published in Edulangue
} 


\section{INTRODUCTION}

The $21^{\text {st }}$ century learning has been a landmark in the use of digital technologies that serve pedagogical purposes, particularly in the sphere of English Language Teaching (ELT, henceforth), which includes the proliferating use of blended learning (Henceforth BL) (e.g., Ellis, 2008; Shih, 2012). This mixture of Face-to-Face (Hereafter FTF) and online learning (synchronous and asynchronous media) derives from industrial world, which has made its way into tertiary education and gained its popularity in the educational context (Macdonald, 2008), and it is currently prevalent in the ELT classrooms (Whittaker, 2013). The synchronous media refer to the online media which can facilitate learning live at anytime and anywhere (e.g., video conference, chat etc.), while the asynchronous media means any e-learning media facilitating either on- or off-line learning (i.e., email, chat boards etc.,) (Macdonald, 2008; Hrastinski, 2008).

The impetus for employing the BL strategy in higher education varies according to the context. Bower, Dalgarno, Kennedy and Lee (2014) and Macdonald (2008) argue that the reasons for the escalating deployment of BL strategy in Australian and UK universities respectively are mainly to facilitate the working professionals who are simultaneously and increasingly undertaking courses. On the other hand, the escalating use of such learning strategy particularly in the ELT context is due to the benefits it offers: fostering the exposure into the target language, collaborative learning (Ellis, 2008), and efficiency (Whittaker, 2013). In addition, Hockly (2001) as cited in Whittaker (2013) enumerates three reasons why BL is employed in ELT classrooms: first, the preference of students to incorporate technologies into their classroom even though it is contextually dependent; second, adaptability it has for students, especially higher education and working students; third, the ministry education's mandate to use blended learning.

Additionally, the use of $\mathrm{BL}$ can be an alternative for allowing those absent students in FTF instructed classrooms to access their missing topics of discussion or learnt materials (Macdonald, 2008). As a result, they are able to follow up their lessons via the virtual learning. Another advantage it affords is to 
assist English teachers or lecturers to distribute materials to their students ahead. This is a common practice in modern world where universities have their own virtual learning platforms by which students and lecturers can catch up before and after the off-line classes. As an illustration, an Australian university, Flinders University where one of the authors undertook his master degree deploys Flinders Learning Online (FLO), which saves students' academic works and facilitates lecturers and students' and peer-led discussion as well as helps the lecturers hand out their weekly topics.

In spite of the fact that BL has a myriad of advantages and has achieved a greater prominence in the ELT classrooms, the discussion of this topic in the EFL context such as in Indonesia, particularly pertaining to its application in the Indonesian higher education setting - its nature and the use of effective and efficient media of e-learning in the blended schooling environmentremains scantily documented.

English in Indonesia is supposed to be obligatory; hence, it serves as a foreign language. In such a context, the main barrier for the students is the absence of English used as a means of daily communication beyond the classroom wall (Oxford, 2003; Brown, 2007). In addition, the time allotment for the teaching of English in Indonesian universities is between one and two hours a week, which is insufficient to sustain the students' learning. Thus, the students find little exposure into the learnt language which impedes their learning and learning outcomes.

Another practical constraint, as we often witness and experience, English lecturers often find it difficult to inform their students and share their materials about the upcoming topic due to the only used form of learning, the traditional classroom practice, FTF or off-line learning, or the absent use of the Internet or elearning mode. The FTF learning is a more common practice in most Indonesian universities which advocates that the application of the Internet is not obligatory. Moreover, there may be a fear that the e-learning would replace the long-term practiced classroom tradition, FTF instruction. However, that is not justifiable for not employing technologies, especially the Internet, in today's era, as it does not help overcome the aforementioned challenges. The 
deployment of BL in such educational setting can play a pivotal role because such a learning strategy can sustain the status quo, FTF learning, without placing the incorporation of technologies in periphery. In addition, it will definitely allow students and teachers to plan the lesson in advanced that will take place in their prospective classes.

Thus, employing BL strategy can be an alternative to the aforementioned barriers in the Indonesian context in the light of its effectiveness in exposing students into the target language beyond the schooling context, assisting lecturers to distribute materials ahead, and maintaining the FTF classroom tradition and deploying the online mode of learning in tandem.

Despite its effectiveness in supporting students' English learning and learning outcomes, the definition and principles of BL are still in need of further elaboration because they do not entail the extent to which e-learning plays a role in such a learning context, particularly in the Indonesian English classrooms. Another issue to be taken into account is selecting the effective and efficient medium of e-learning in the BL EFL classrooms in the country. Despite the availability of an enormous numbers of existing freeelearning media, such as wikis, YouTube, blog, etc., Facebook (FB, henceforth) seems to be the most effective and efficient add-on to the e-learning mode in the BL EFL classrooms in the Indonesian higher education setting. It is not to say that the other aforementioned online media are not effective in such learning context though.

For this reason, this paper discusses the nature of $\mathrm{BL}$ strategy with reference to adult English classrooms in Indonesia; argues why $\mathrm{FB}$ can be an effective and efficient add-on to elearning mode in the classroom context by drawing on some current research; and presents an example of its application and reflection as applied in my English-speaking classroom at UIN Mataram (Mataram State University for Islamic Studies).

\section{The Nature of Blended Learning}

In spite of its increasing use in some advanced countries, such as America, UK and Australia, there are a myriad of different interpretations pertaining to the definition of BL. Padede (2012, p. 
165) opines that the existence of many distinct definitions is due to its association to e-learning, which results in the use of several terms adhered to the strategy, namely "computer-based learning, technology-based training, and computer-based training."

It is essential to bear in mind that in a BL classroom, there should be two modes of learning: the FTF and e-learning modes. Although Macdonald (2008) provides the least definition, we may say, of BL as a mixture of FTF and e-learning activities (using the Internet synchronous and asynchronous media), it seems there needs to be more specific definition of the term because it does not entail the extent to which the e-learning mode plays role in the context, where the FTF instruction is prominent and English acts as an EFL such as in Indonesia. Nonetheless, we agree with the notion of BL above; however, we prefer to regard it as the starting point to further elaborate the ideal definition that meets the context above. Hence, it is not just simply a combination of FTF with e-learning instruction.

Smith and Kurthen (2007) as cited in Whittaker (2013), for example, by drawing on the existing terms: hybrid or mixed learning, e-learning, define it by using percentage.

1. Web-enhanced learning, in which the e-learning mode is only deployed as a course platform or Learning Management System (LMS), which is mainly used to help teachers hand out materials to students.

2. $\mathrm{BL}$ where the percentage use of e-learning is less than 45 percent.

3. Hybrid learning where the online mode of learning outweighs the FTF mode between 45 to 80 percent.

4. Fully online learning, where less than 20 percent of the subject is on FTF basis.

In addition to that, Whittaker (2013), by drawing on the existing definitions of $\mathrm{BL}$, opines that the term refers to a mixture of FTF instruction and computer assisted learning, either online or offline activities. However, the combination of FTF and off-line activities facilitated by computers cannot be regarded as BL as both happen in the FTF basis, not virtual world with reference to Macdonald definition. Say, doing certain off-line exercises in a computer lab is simply FTF activity as it does not encompass 
online tasks, which does not correspond to the basic concept of BL as described by Macdonald above.

Some enthusiasts in the area also use the term technology as the supplementary mode to FTF instruction. For instance, Sharma and Baret (2007) regard BL as a blend of off-line instruction and proper technologies. Nonetheless, the term "technology" is still general, which also may lead to the use of off-line activities such as using computers to write an essay. Another description of BL presented by Dudeney and Hockly (2007), as cited in Whittaker (2013), who define BL as one fourth of learning is operated on the FTF mode, and three fourth of the learning is conducted in the online mode. However, this is not applicable within the context of EFL, particularly in Indonesia, since the FTF means of learning is paramount in the Indonesian education context. In addition, the FTF learning still becomes the leading mode of learning across the globe.

We personally advocate that e-learning mode in the BL classrooms should provide supplementary support for students' learning as described by Macdonald (2008) and Sharma and Barrett (2007). Sharma and Barett (2007) opine that the online learning mode should be supporting to the FTF learning mode, while the latter mode is supposed to be the leading mode in the learning context. Similarly, Macdonald (2008) repeatedly deploys the term "supports" in relation to the use of BL which should serve supports toward students' learning.

With respect to the above discussion, the following principles are enumerated:

1. BL is a blend of FTF instruction and online learning (Internet synchronous and asynchronous media).

2. Online learning mode serves as a support to the FTF instruction.

3. FTF instruction still becomes the leading mode in the blended learning.

4. The use of e-learning mode is not only for assessment, but also for learning.

Grounded in the above principles, we would like to propose the appropriate definition of BL that fits the Indonesian context as the following: 
A blend of FTF instruction and any synchronous or asynchronous e-learning media operated by various means of technological devices, which provides supplementary supports for the students' learning in which the former mode of learning acts as the leading learning mode.

The definition above reflects the extent to which the role of e-learning mode in the BL English classrooms in Indonesia: it plays a role as a supplementary support to the FTF instruction. In so doing, the role of e-learning media in the EFL context, particularly in Indonesia, can facilitate and support students' learning by exposing them to the target language without depriving the FTF instruction as the common and official tradition of learning, which leaves the FTF learning mode as the leading means of learning in the context.

\section{Current Research on the Deployment of FB as a Virtual Learning Platform}

FB was invented by Mark Zuckerberg in 2004. Since its inclusion as a part of social media for the last 11 years, it has gained its popularity among young students (Karal, Kokoc, \& Cakir, 2015). The current statistics shows that there have been almost 1.6 billion people globally using this networking site per April 2016, and Indonesia ranked four with 77.58 million of active users (Statista, 2016). However, FB users operate it mainly for social interaction (Pempek, Yermolayeva, \& Calvert, 2009), not for educational purposes. This is even legitimated by the initial finding of the study by Karal at al. (2015), which unveiled that the students used FB primarily in order to share, get new friends and keep in touch with friends, not for learning. Framed by its role and fame above, a great number of research has been apparent on the use of FB as a medium of e-learning in ELT classrooms (e.g., Shih, 2011; Karal et al; Aziz, 2013). Nonetheless, Shih (2011) mentioned that many denied that Web 2.0 technologies such as FB could cater formal education. In fact, many reports provide evidence that the increasing use of social media corresponds to the low achievement of students (e.g., Rouis, Limayem \& Salehi-Sangari, 2011). Social media, such as FB, deprive students' learning time. However, associating FB with FTF classroom activities, blended learning, as a 
medium of instruction in higher education, will likely foster their learning and learning outcomes (Shih, 2011). Therefore, it is pivotal to generate evidence to advocate the effective use of FB by drawing on some current research on its application as e-learning medium in general and in the ELT BL classrooms in particular.

Wang, Woo, Quek, Yang, and Liu. (2012) advocate that many available Learning Management System (hereafter LMS) or virtual learning platforms are expensive. Hence, schools cannot continually use them for the long run. In addition, they do not afford students to the creation of a course and students' enrolment because they are only accessible for instructors and administrators. Drawing on the successful implementation of FB in such context, they argue that FB can be an alternative to the aforementioned challenges in the light of its affordances for teachers to create and enrol students in a course, particularly in a small size class. To generate the empirical evidence on its possible implementation as an LMS, Wang et al. (2012), drawing on its viable functions as pedagogical, social and technological means, did research and unveiled that FB can be straightforwardly deployed as an LMS, a virtual platform used to post announcements, share materials, and manage and discuss any lessons with students, at a Singaporean teacher education institute; additionally, the students found it helpful due to its viability. Furthermore, its application as an LMS has some barriers to take into account such as its inability to serve for uploading certain types of files, facilitate the discussion in a sequence thread, and discomfort students in terms of privacy. The students assume that the teachers and other friends would be able to access to their personal matters. However, to be enrolled in the FB group, the teacher and students or everyone in the group does not necessarily to be friends on FB (Wang et al., 2012). In so doing, the issue of privacy can be tackled.

FB is also applicable as a research instrument. Hiew (2012), for example, employed FB as a tool to collect data pertaining to students' perceptions of the current practice of ELT in Malaysia. Although FB was not included as one of the variables in the study, such implementation proves that FB can assist respective researchers to garner the intended data. The reason for employing $\mathrm{FB}$ as a data collection instrument in the study was due to its 
popular use among the Malaysians.

A myriad of research also generates empirical data that support the use of FB as a virtual platform in ELT classrooms. Karal at al. (2015) investigated the impact of Facebook used for group learning on the appropriate usage of English language of high school students. It was discovered that the social network cultivated students' oral and written skills and relationship with their teachers and among themselves as students. In addition, it proves that FB can be a miniature of social life by which students can develop their proper language usage in the real social context as long as it is designed as a group of learning that caters the interactive, reflective tasks and effective communication and aspiration. Another study by George (2015), involving 50 Japanese students majoring in English who actively used FB, discovered that the social medium developed students' English language use and communication with their counterparts. In addition, the students found it convenient to use $\mathrm{FB}$, yet they were unable to operate oral or verbal communication. The use of $\mathrm{FB}$ as a means of informal language learning motivates students to practice their English.

Some experimental studies also provide empirical evidence in favour of the application of FB in ELT classrooms. An experimental study by Suthiwartnarueput and Wasanasomsithi (2012) on the use of FB as a means of discussing English grammar and writing involving 83 low-intermediate undergraduate students in a Thai university, which found that there was a significant difference between the pre-test and post-test given $(t=6.65$, $\mathrm{p}=0.00)$. Overall, the participants generally discussed the structure of sentences, meaning of the words, parts of speech and relative clause. Given the students' achievement in writing and grammar is significantly correlated with $(r=0.399$ in the pre-test and $r=0.859$ in the post-test), which indicated that discussion via FB promotes students' writing and grammar. Students also expressed their enjoyment to use FB as an exciting medium of learning because they can discuss with their teacher and other students with higher grammatical knowledge.

A classroom action research by Sumakul (2012) which was done in three different English departments in Indonesia to investigate how FB can be incorporated into Grammar lessons and 
to examine how FB can be integrated into a range of Grammar lessons and what activities can be accommodated via FB. Another similar action research study by Aziz (2013), involving C-class students of Brawijaya University Indonesia by means of FB group as the tool in the BL strategy, was conducted to examine its impacts on the students' achievement on learning present tenses. It was unveiled that the strategy significantly boosted the students' achievement given the test result that showed all the students gained the above expected score (60), in which there were only $22 \%$ of the students achieved the above score. In addition, the students were also found to enjoy and to be satisfied with the inclusion of $\mathrm{FB}$ as the medium of instruction in the light of the provision of shared-links for grammar practices that improved their comprehension, opportunities to practice their English such as asking questions, discussing and sharing interests with group members and practice their English with a native speaker.

Shih (2011) conducted a mixed-method research to examine the impact of incorporating FB and peer-assessment into English writing classroom. 33\% of the meeting throughout the semester was FTF classroom instruction only, and $67 \%$ of the rest were conducted by a combination of $\mathrm{FB}$, peer assessment and classroom instruction, which involved 23 students undertaking English at a Taiwanese technological university. It was discovered that the students found it interesting and effective for studying writing. Furthermore, both in-class learning activities and cooperative learning through FB stimulated their writing skills and knowledge which brought about an improvement in their motivation and interests. In addition, the integration of FB as the BL strategy with English writing class was effective in improving students' writing skills given the significant difference and score difference $(\mathrm{p}<.05)$ and $35,7,24.5$, between the pre-test and post-test of the students in the three groups; groups with low, medium and high score respectively. In addition to that, the findings generated by the survey in the study showed that the students thought the integration of FB and peer assessment could engage them more actively in learning. In addition, the learning cooperatively could encourage students to communicate, to strengthen friendship, to believe each other, to interact, to learn actively and to have positive 
attitudes towards learning. Furthermore, this means of blended instruction could mediate and help students to learn how to organise their learning.

A study by KAO and CRAIGIE (2014) in a Taiwanese university also discovered that the use of $\mathrm{FB}$ as the medium of instruction could enhance the students' English achievement. Given the fact that English functions as the foreign language where there is a limited access to the learnt language, the researchers argue that $\mathrm{FB}$ provides learners with an extensive exposure to the target language by enabling them to discuss, comment, and question in English with native speakers across the globe.

In short, it has been evident that FB applied as either an LMS, research instrument or e-learning medium in the BL ELT classrooms in various educational contexts is applicable, and that it can foster students' learning and learning outcomes, enjoyment, and motivation through the established collaborative and learning community that it affords. Nonetheless, the arguments favouring why $\mathrm{FB}$ is an effective Web 2.0 technology for blended EFL classrooms in Indonesia is needed as the core contention of this paper.

\section{Why FB is an Effective Web 2.0 Technology for Blended EFL Classrooms in Indonesia.}

There are a great number of reasons that advocate why FB is an effective and efficient e-learning means in the blended EFL classrooms in the Indonesian Higher education context, which include being the most favoured social networking site, straightforward use, being a Web 2.0 technology, and efficiency.

$\mathrm{FB}$ is one of the most viable social media to be used in the $\mathrm{BL}$ classroom in the light of its favourable use. In comparison to other social media, such as Wikis, blogs, YouTube etc., FB gains more popularity among young people (Karal et al., 2015). In fact, Indonesia is among the top five countries with active users worldwide. Based on the statistical evidence, Indonesia has reached the fourth position along with 77.58 million active users (Statista, 2016). With this in mind, the deployment of FB as a medium of elearning in the BL in the Indonesian Higher education context can cover all students. As a result, teachers ought not to be so weary to 
seek for appropriate means of e-learning in the BL classroom. As an illustration, in one of the authors' BL classroom, at the outset, he asked his students about which type of e-learning media that they were familiar with. All of them responded that FB was their most familiar networking medium. Another evidence of its use due to being the most favourite social media platform, Healy in Oxford University Press (2013) opined that one reason for using FB as the virtual platform in his language class was in fact that all of his students owned such a social medium. Hence, implementing FB can be an effective medium of e-learning as it can ease teachers' work; teachers can directly deploy FB without giving training to the students on how to use it as both have been familiar with its use.

Another reason why FB is the most effective and efficient means of e-learning in the BL classroom is because of its straightforward application. Unlike many other online media, FB does not require its prospective users to possess high technological knowledge. They simply register by using their email address or mobile phone number. In fact, $\mathrm{FB}$ has reached different people with distinct socioeconomic status from young to adult; from uneducated to educated people; and from poor to well-off community.

FB, like many existing social networking sites such as Twitters, blog, YouTube etc., pertains to the Web 2.0 technologies which allow their users to share and develop knowledge within a larger community (Suthiwartnarueput \& Wasanasomsithi, 2012). Similarly, Shih (2011) argues that FB as the Web 2.0 can facilitate collaboration and interaction among its users. It allows students to upload, share, comment, and download materials. As discussed in the review of current research as a part of this paper, FB encourages students to work collaboratively. In addition, Healy as in the Oxford University Pres (2014) opines that FB can be used as an LMS which is similar to that of Wang et al. (2012). Healy created FB group for each of his class by which students could upload messages, photos, videos and word files. Furthermore, FB can also act as both synchronous and asynchronous medium of elearning because of its components such as FB chats and message icon it has. Due to such affordances as Web 2.0 and functions as synchronous and asynchronous media, FB can be an effective an 
efficient virtual learning tool in the BL classroom environment in Indonesia.

Another reason advocating the effective and efficient use of $\mathrm{FB}$ as the medium of e-learning is that the efficiency it affords. Similar to other social media, it is free of use. Everyone has access to it provided that he or she has an FB account and owns the Internet access. Wang et al (2012) argues that most LMSs are costly which make schools unable to deploy it as their virtual learning platform. Furthermore, in Indonesia where most universities do not run an LMS due to the reason above, using FB can be an alternative because of the efficiency it affords and its applicability as an LMS such as in the study by Wang et al. (2012).

In conclusion, $\mathrm{FB}$ can be an effective and efficient medium of e-learning in the BL EFL classrooms in Indonesia in that it becomes the most preferable social media, which all students certainly possess. In addition, FB is easy to operate. Teachers and students do not have to be highly knowledgeable in the use of technologies in order to be able to operate it. FB also belongs to the members of Web 2.0 technologies, which allows its users to upload, download, comment and share any materials such as images, videos, and word files. The efficiency it offers also makes $\mathrm{FB}$ be an effective and efficient medium of e-learning in the Indonesian Higher education.

\section{An Example of the use of FB in a blended EFL English classroom.}

In this section, we provide an example of FB deployment carried out in one of the authors' speaking class (non-credit course) in UIN Mataram (Mataram State Islamic University), in Lombok Indonesia. Having students practice their English with foreigners by visiting some tourism objects is a common practice in an Indonesian preservice EFL speaking classroom, particularly in Lombok, given the fact that in the island is a plethora of majestic tourism sites. We also discuss the barriers faced with this strategy. The snapshots of the students being and communicating with some tourists are enclosed in this section. Ultimately, this section illustrates how FB group could be used to collect students' speaking practice as assigned by the faculty as the requisite to the 
accomplishment of the course.

To begin with, it is paramount to get to know the learning context. The class consisted of 15 students majoring in English and education with elementary level of English. The course was a noncredit course, the Intensive Spoken Communication Practice (ISCP). It was designated to help students develop their communicative competence necessary in supporting their prospective studies in the institution. The classroom happened to be one and half month in which the students attended the class once a week on Friday morning.

As for the online activity, a private FB group was created as an LMS by which the materials could be distributed to the students, sustain communication with them and support their learning beyond the classroom. With the widespread possession of digital devices, such as mobile phones, along with the availability of the Internet, via the FB group, the students were instructed to seat in a group of five to go to a tourism site to practice speaking with at least one native speaker following certain topic in the class: what they like and dislike about Lombok, how have they been in Lombok, and how many places in the island have they been to. They were too asked to videorecord their conversation with their smartphones and upload onto the FB group. Subsequently, all of the students were encouraged to give feedback or comment on each of the uploaded video followed by the lecturer's constructive feedback through the available comment box.

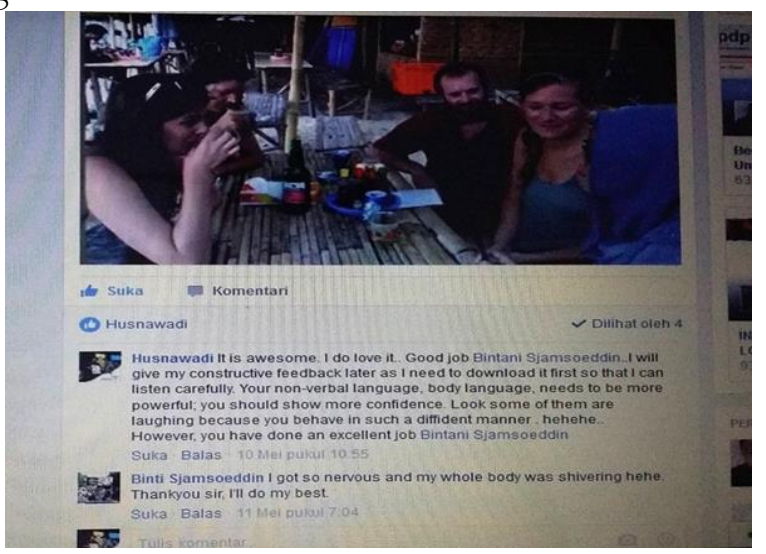

A video recorded by a student interviewing foreigners in Gili Terawangan and uploaded onto the FB group. 


\section{Edulangue Vol 1 (1) 2018}

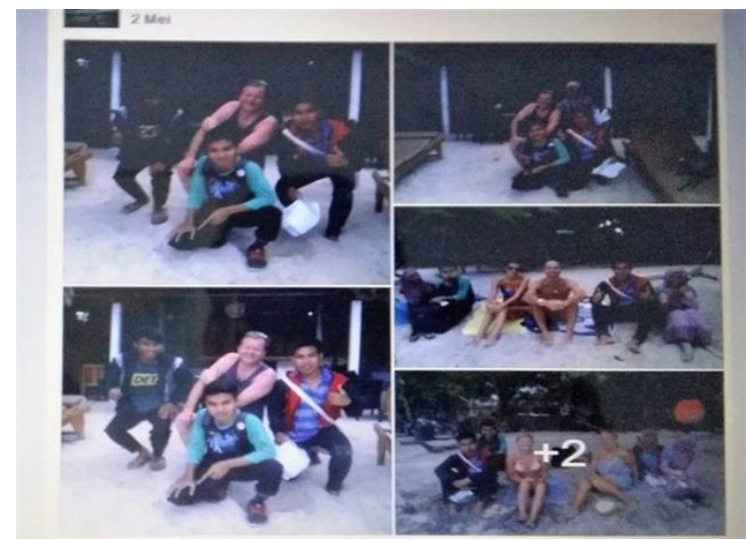

A group of students posing with some foreigners

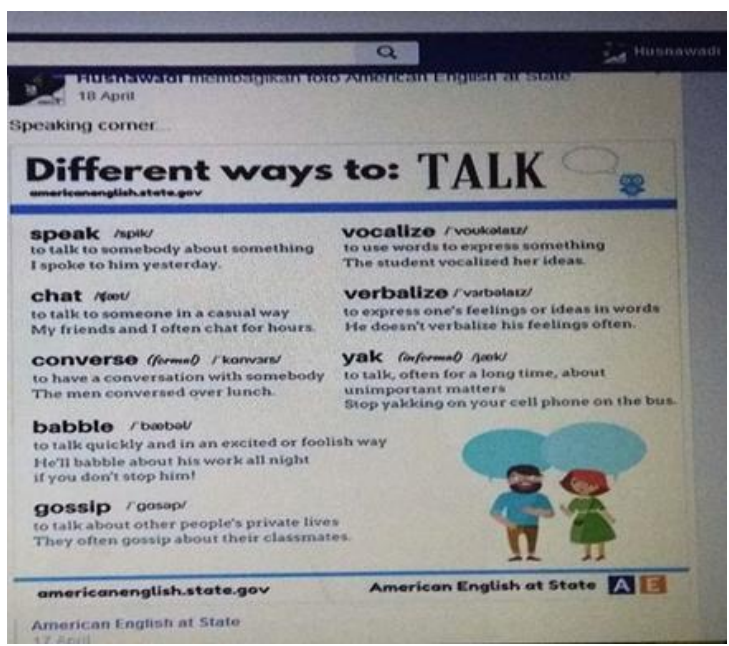

An English speaking source posted by the lecturer

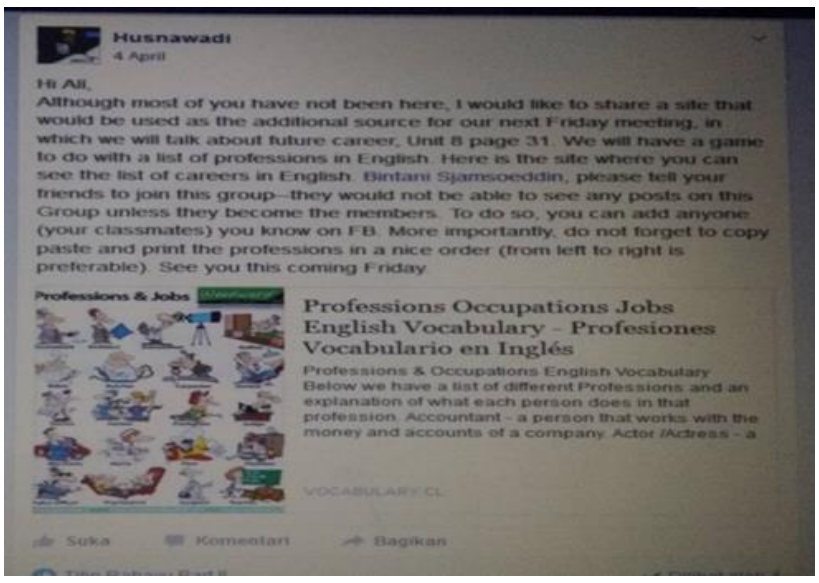


In the following week, in the FTF instruction, the lecturer had each of the students present his or her story pertaining to his or her assigned task interviewing the foreigners. In this session, students were required to apply paste tense accurately. The other students in the class were encouraged to ask any questions related to the presentation.

\section{REFLECTION.}

As the instructor in the course, the lecturer definitely became the facilitator of the learning although he paid attention on the language use and usage: commenting on the language function and grammar of the students at the end of the class collectively either in the online or in the FTF mode. he, however, initially allowed the other students to comment or give feedback following each of the uploaded videos and the presentation in the class (peerassessment).

This BL strategy also allowed the lecturer to sustain communication with the students and to distribute or share materials and other available online resources before the class took place. Unlike in the only FTF instruction, the lecturer often missed communication with his students. he could not inform his students regarding his possible absence in the following class. Although was allowed to communicate via a mobile-phone to only the class leader, it took time to let to know all members of the class at the same time. More importantly, students could get access to the available authentic online resources. In so doing, they could foster their linguistic repertoire.

Precisely, this means of learning helped expose his students into the target language beyond the schooling wall. In fact, in the context of EFL as in Indonesia, learners find it difficult to access to English use due to its absence in daily encounters. Deploying FB as a medium of learning in his class could serve such a useful purpose.

Nonetheless, few of his students found it difficult to get the access to the Internet. This can be seen as the shortcoming of its application. However, this does not mean that this means of learning does not work in the context. The students should not be supposed to be online every day, rather at least once a week, so 
they can see any posts and discussions. Furthermore, he found some of his students fazed by the activity (videorecording). Some of the introvert students may not be able to perform such a task. However, the classroom practice is not limited to the single practice as in his class. A myriad of learning activities can be done through the virtual learning and FTF. This includes writing, listening, peer-assessment etc.

In short, this illustrates that FB can be used effectively and efficiently as a medium of instruction in such a BL ELT classroom as it can sustain students to students' and students to teachers' communication beyond the schooling context. In addition, it can facilitate the teacher to share and plan materials in advanced where it remains as one practical and significant constraint in the Indonesian universities.

\section{CONCLUSION AND IMPLICATIONS.}

The $21^{\text {st }}$ century learning characterized by the escalating use of the Internet has led to the deployment the digital devices and BL strategy in the sphere of education, particularly in ELT classrooms. The nature of BL that serves the supplementary support to FTF instruction has assisted both the teachers and students to foster the teaching and learning processes, particularly in the Indonesian universities where the FTF classroom remains the prominent pedagogical practice. For the teacher, he or she can sustain communication, share materials and related resources; and for the students, they can interact, communicate in a collaborative way, and expose themselves into the target language beyond the classroom context. With reference to the current research on the use of $\mathrm{FB}$ as the virtual learning medium in the $\mathrm{BL}$ classroom and the arguments favouring its application, it is obvious that it can be an effective and efficient means of e-learning in the learning context. The example of its application in the English-speaking classroom helps shed some light on how to apply FB as an LMS and e-learning medium. In short, this paper has generated proper nature of BL which meets the Indonesian context and has brought about evidence on the successful deployment of FB as the elearning medium in the ELT BL classrooms, which may give insightful ideas for the English teaching practitioners or teachers to 
Husnawadi \& Sugianto, Facebook: An Effective Web 2.0...

implement particularly in Indonesian adult English classrooms.

\section{REFERENCES}

Aziz, A. L. (2013). Implementing Blended Learning Strategy to Increase Students' Achievement on the English Tenses at Brawijaya University. Paper presented at the International Conference on Language, Literature \& Linguistics 2013, International Centre for Research Development Malabe, Srilanka. Retrieved from http://uniqueca.com/archieves/pdf/2013/Proceeding\%20 LLL\%202013.pdf

Bower, M., Dalgarno, B., Kennedy, G., Lee, M, J, W., \& Kenney, J. (2014). Blended synchronous learning: A bandbook for educators. Rertireved from https://blendsync.org/handbook

Brown, H. D. (2007). Teaching by principles: An interactive approach to language pedagogy (3rd ed.). New York: Pearson Education.

Ellis, L. (2008). Writing instruction and learning strategies in a bybrid EAP course: A case study with College-Bound ESL students (doctoral dissertation). Retrieved from http://eresources.perpusnas.go.id:2057/docview/304403863?pqorigsite $=$ summon\#. (3330385)

George, J. (2015). Facebook to Facebook Encounters in Japan: How an Online Social Network Promotes Autonomous L2 Production. In L. Piasecka, M. Adams-Tukiendorf, \& P. Wilk (Eds.), New Media and Perennial Problems in Foreign Language Learning and Teaching (pp. 91-112): Springer International Publishing.

Healy, T. (2013, October 24). Using facebook and smart devices for blended learning. Oxford University Press. Retrieved from https: / oupeltglobalblog.com/2013/10/24/usingfacebook-and-smart-devices-for-blended-learning/

Healy, T. (2014, August 27). Using social media and smart devices effectively in the classroom. Oxford University Press. Retrieved from https://oupeltglobalblog.com/2014/08/27/usingsocial-media-and-smart-devices-effectively-in-theclassroom/

Hiew, W. (2012). English language teaching and learning issues in Malaysia: Learners' perceptions via facebook dialogue 
journal. Researchers World, 3(1), 11-19.

Hrastinski, S. (2008). Synchronous and asynchronous e-learning. EDUCAUSE Quarterly, 31(4),51-55. Retrieved from https://net.educause.edu/ir/library/pdf/eqm0848.pdf

Kao, P., \& Craigie, P. (2014). Effects of English usage on Facebook and personality traits on achievement of students learning English as a foreign language.Social Behaviour and Personality, 42(1), 17-24.

Karal, H., Kokoc, M., \& Cakir, O. (2015). Impact of the educational use of Facebook group on the high school students' proper usage of language. Education and Information Technologies, $\quad 1-19 . \quad$ Retrieved from http://link.springer.com/article/10.1007/s10639-015-9428$\mathrm{y}$

Leading social networks worldwide as of April 2016, ranked by number of active users in millions. (2016, July 20). In Statista.

Retrieved fromhttp://www.statista.com/statistics/272014/globalsocial-networks-ranked-by-number-of-users/

Leading countries based on number of Facebook users as of May 2016 (in millions). (2016, July 20). In Statista. Retrieved from http://www.statista.com/statistics/268136/top-15countries-based-on-number-of-facebook-users/

Macdonald, J. (2008). Blended learning and online tutoring: Planning learner support and activity design (2nd.). England: Gower Publishing Limited.

Oxford, R. L. (2003). Language learning styles and strategies: an overview. Retrieved from http://web.ntpu.edu.tw/ language/workshop/read2.pdf

Pardede, P. (2012). Blended learning for ELT. Joumal of English Teacbing, 2(3), 165-176. Retrieved from https://drive.google.com/file/d/0B7pJkzTapTsOY19Vekl SVFQ4NXM/view?pref $=2 \&$ pli $=1$

Pempek, T. A., Yermolayeva, Y. A., \& Calvert, S. L. (2009). College students' social networking experiences on Facebook. Journal of Applied Developmental Psychology, 30(3), 227-238.

Rouis, S., Limayem, M., \&Salehi-Sangari, E. (2011). Impact of 
Facebook Usage on Students' Academic Achievement: Role of self-regulation and trust. Education and Psychology., 9(3), 961-994.

Sharma, P and Barrett, B (2007) Blended Learning. Oxford: Macmillan.

Shih, R. C. (2011). Can Web 2.0 technology assist college students in learning English writing? Integrating Facebook and peer assessment with blended learning. Australasian Journal of Educational Technology, 27(5), 829-845.

Sumakul, D. T. Y. (2012). Facebook in grammar teaching: A Look at three EFL classrooms in Indonesia. The New English Teacher, 6(1), 60-81.

Suthiwartnarueput, T., \& Wasanasomsithi, P. (2012). Effects of using Facebook as a medium for discussions of English grammar and writing of low-intermediate EFL students.Electronic Journal of Foreign Language Teaching, 9(2), 194-214.

Wang, Q., Lit Woo, H., Lang Quek, C., Yang, Y., \& Liu, M. (2012). Using the Facebook group as a learning management system: An exploratory study.British Journal of Educational Technology, 43(3), 428-438. doi: 10.1111/j.14678535.2011.01195.x

Whittaker, C. (2013). Introduction. In Tomlinson, B \& Whittaker, C (Eds.), Blended learning in English language teaching: Course design and implementation (pp. 9-24). London, England: British Council. 